\title{
Experimental study of materials radiation resistance in reactor mixed fields for the construction of the SPES facility at LNL
}

\author{
A. Zenoni ${ }^{*}$, F. Bignotti, A. Donzella, G. Donzella, M. Ferrari, D. Paderno and S. Pandini \\ Department of Mechanical and Industrial Engineering, University of Brescia, \\ via Branze 38, 25125, Brescia, Italy \\ *aldo.zenoni@unibs.it \\ A. Andrighetto, M. Ballan, S. Corradetti, F. D’agostini, M. Manzolaro, A. Monetti, \\ M. Rossignoli and D. Scarpa \\ Legnaro National Laboratories of INFN, Viale dell'Università 2, \\ 35020, Legnaro (Padua), Italy \\ D. Alloni, A. Salvini and F. Zelaschi \\ LENA Laboratory, University of Pavia, via Aselli 41, 27100, Pavia, Italy
}

Published 10 July 2018

\begin{abstract}
The Selective Production of Exotic Species (SPES) facility, now under construction at Legnaro National Laboratories of INFN, is a second-generation accelerator for the production of neutronrich ion beams. The radioactive nuclear species are produced by fission of a ${ }^{238} \mathrm{U}$ target, on which a $200 \mu \mathrm{A}$ primary proton beam of $40 \mathrm{MeV}$ energy impinges. Materials and components constituting the Target and Ion Source assembly and the Front-End supporting structure are subjected to serious radioactive damage due to intense neutron and photon fields present under operating conditions. In the framework of the SPES project, experimental campaigns aimed at testing the radiation hardness of critical materials and components of potential use in the construction were started. Irradiations were conducted in a reactor mixed field of neutrons and photons in order to reproduce, as close as possible, the actual environmental service conditions. Results obtained for different types of elastomeric materials used for construction of vacuum Orings, as well as preliminary results obtained for lubricating oils and greases, are presented. Materials under consideration are both conventional ones as well as materials specifically developed for applications in the presence of ionizing radiation. The latter materials were previously tested mainly in gamma radiation fields.
\end{abstract}

Keywords: Radioactive ion sources; radiation resistance; elastomers; lubricants; neutron and gamma fields; dosimetry.

PACS numbers: 29.25.Rm, 81.05.Lg, 61.80.-X

\section{Introduction}

The Selective Production of Exotic Species (SPES) facility at the Legnaro National Laboratories (LNL) of the Istituto Nazionale di Fisica Nucleare (INFN), ${ }^{1}$ now in the construction phase, is a second-generation accelerator for the production of neutron-rich Radioactive Ion Beams (RIBs). The radioactive nuclear species are produced by fission

This is an Open Access article published by World Scientific Publishing Company. It is distributed under the terms of the Creative Commons Attribution 4.0 (CC-BY) License. Further distribution of this work is permitted, provided the original work is properly cited. 
of a ${ }^{238} \mathrm{U}$ target in the form of a series of thin, porous ${ }^{238} \mathrm{UC}_{\mathrm{x}}$ discs, on which a $200 \mu \mathrm{A}$ primary proton beam of $40 \mathrm{MeV}$ energy impinges. ${ }^{2-5}$ The ${ }^{238} \mathrm{U}$ fission, at the rate of about $10^{13}$ fission/s, generates a highly radioactive environment with neutron and gamma fields whose fluxes (close to the target) are approximately $10^{10}$ particles $/\left(\mathrm{cm}^{2} \mathrm{~s}\right)$.

Materials and components constituting the Target and Ion Source (TIS) complex and the Front-End (FE) supporting and handling structure ${ }^{6}$ are subject to serious damage due to intense neutron and gamma radiation. The materials and components most likely to be adversely affected by these forms of radiation are those composed of polymers, such as vacuum O-rings, cable insulators, optical fibers, and lubricating oils and greases. Experimental campaigns aimed at testing the radiation hardness of commercially available materials and components have started. This paper documents the results of the first such study focused on elastomeric materials used for the construction of vacuum Orings, as well as some preliminary results obtained for lubricating oils and greases.

At present, in the context of accelerator technology and nuclear physics research, the main sources of information on the radiation hardness of materials and components are the CERN Yellow Reports (see Ref. 7 and references therein) and the various manufacturers' product data sheets.

However, besides the obsolescence of some of the data contained in the CERN Yellow Reports, the prediction of the life expectancy of materials and components in radioactive environments is generally performed by accelerated-aging tests. The predictability of these tests is influenced by several factors, such as the type of radiation present, dose-rate effects, presence and penetration of oxygen in the bulk material (i.e., the diffusion limited oxidation effect, or $\mathrm{DLO}^{8}$ ), synergistic effects of temperature and radiation, and sample geometry. ${ }^{9,10}$ In some cases, the differences in radiation-induced effects on the physical properties of polymeric materials under oxidizing versus nonoxidizing conditions may be relevant. Therefore, to obtain significant and reliable data, the testing conditions must be carefully chosen to ensure that the degradation processes involved in the accelerated-aging tests are as much as possible similar to those occurring under regular service conditions.

For this study, irradiation of the materials samples was conducted in the neutron and gamma mixed field of the TRIGA Mark II research nuclear reactor at the LENA Laboratory (Pavia University, Italy). Researchers were careful to account for the main radiation field components expected under operating conditions in the FE and TIS complexes.

Previous research produced a huge amount of data about the effects of radiation on organic materials. In general, the data were obtained using only gamma radiation, both for practical reasons (i.e., gamma radiation does not generate sample activation) and for a generally accepted rule of thumb that states "for equal energy absorbed, there will be equal radiation effect". However, the latter statement must be considered only as a first approximation. ${ }^{11}$ In the research documented in Ref. 12, the radiation damage produced in elastomers by reactor radiation was compared with the damage produced by different gamma sources. The ratio between the mixed-field dose and the reference gamma dose 
inducing the same damage effect was measured and found to be within a factor of two. On coolant materials, the damage caused by fast neutron dose was four times more severe than that caused by the same gamma dose, as reported in Ref. 11 (p. 306).

\section{SPES TIS Complex and FE Supporting and Handling Structure}

The TIS is the core of the entire SPES facility. It is the system component in which uranium fission occurs, producing exotic neutron-rich nuclei as fission products. ${ }^{6}$ The generated unstable atomic species are extracted from the target and ionized, in order to be subsequently selected and accelerated to produce the RIBs. Figure 1 depicts a crosssection of the target chamber that contains the segmented target unit, transfer line tube, and ion source. Two VAT valves, one corresponding to the RIB exit pipe and the other one connected to the entering proton beam pipe, are also shown. The two VAT valves are needed to isolate the target chamber when it is removed from the FE complex (at the end of the 15-day operation and 15-day cooling) in order to prevent the release of radioactive contaminants. The target chamber is designed to be easily removable by an automatic handling system.

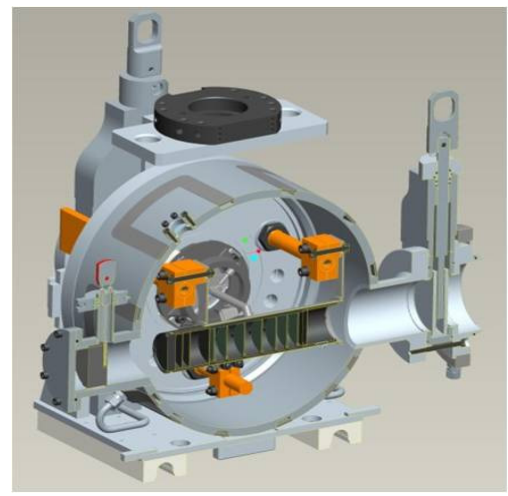

Fig. 1. Cross-section of the target chamber containing the segmented target unit and the ion source.

The most critical components of the TIS are the elastomeric vacuum O-rings; they maintain the required vacuum seal in the target chamber and in the connected Primary Proton Beam (PPB) and RIB pipe lines. The elastomeric O-rings of the two VAT valves are particularly critical. They function in dynamic conditions in which the recoverable deformation after irradiation becomes particularly crucial. The working temperature range foreseen in the positions where the O-rings are located is $25^{\circ} \mathrm{C}$ to $80^{\circ} \mathrm{C}$.

Figure 2 depicts the SPES production area with the FE complex supporting the target chamber and providing all of the necessary connections: PPB and RIB pipe lines; high vacuum; electrical power to heat the target unit and the surface ion source; water for cooling; and a $40 \mathrm{kV}$ high-voltage connection to provide the extraction and initial acceleration of the radioactive ions. 


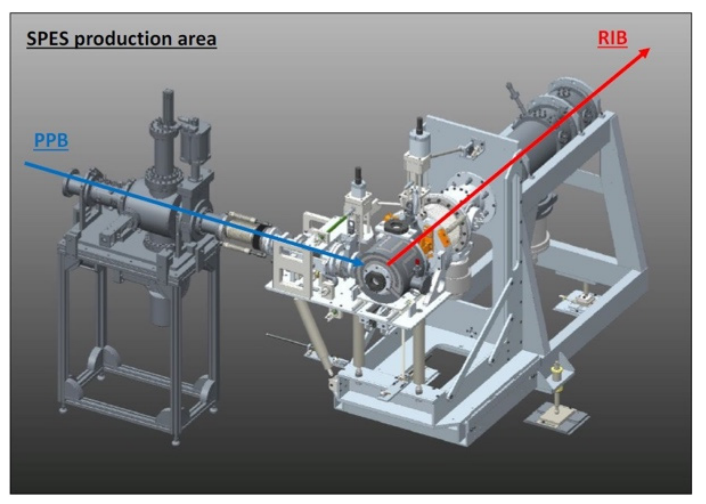

Fig. 2. SPES production area; the FE complex is shown with the target chamber installed.

The target chamber is subjected to extreme thermo-mechanical and radioactive working conditions and must be removed from the FE complex and replaced after a 30day life cycle by means of a fully automatic handling system. Several mechanical devices equipping the FE provide the capability to uncouple the electrical, hydraulic, and vacuum connectors and the RIB pipe line; disconnect the PPB channel interface; move the RIB extraction electrode and the diagnostic sensors; dismount the target chamber from the FE; and finally remount a new target chamber.

Pneumatic motors, Acme screws with brass bushings, rolling bearings, linear ball bearings, rotating speed reducers, VAT valves, and diagnostic systems' sliding shafts all require lubrication using the appropriate oils and greases. The radiation hardness of these organic products is a critical issue; the radiation-induced modification of their chemical and lubricating properties may seriously compromise the whole system's operation. Because of the degradation of materials, the FE subassembly closest to the target chamber should be removed and substituted every seven years of operation; however, the radiation hardness of lubricating oils and greases employed in this subassembly is still an open issue.

\section{Selection of Materials to be Tested for Radiation Hardness}

\subsection{Elastomeric materials used for vacuum O-rings}

Four elastomeric materials were selected for the irradiation tests: one flouroelastomer polymer (FPM), Viton ${ }^{\circledR}$, and three ethylene propylene diene monomer rubber (EPDM)based elastomers. The materials under consideration are used for commercially available vacuum O-rings. EPDM- and FPM-based elastomers are currently employed for this type of application because of their excellent resistance to radiation and temperature, respectively. ${ }^{13}$ Although EPDM-based elastomers are considered more radiation resistant than FPM-based elastomers, ${ }^{14,15}$ they absorb a higher neutron dose in the same radiation 
field, due to their greater hydrogen content. For this reason, the role of EPDM-based elastomer as the best choice might be reconsidered.

Table 1 is a list of the elastomers selected for this study. VITON and EPDM1 are the standard products in use at LNL, whereas EPDM3 is certified by the manufacturer as radiation resistant up to $1.6 \mathrm{MGy}$ in ${ }^{60} \mathrm{Co}$ gamma fields.

Table 1. Elastomers tested for radiation resistance in reactor mixed fields. VITON and EPDM1 are the standard materials for O-rings in use at LNL.

\begin{tabular}{|c|c|c|c|c|c|}
\hline Product & Type/manufacturer & Curing & $\begin{array}{l}\text { Mechanical } \\
\text { properties }\end{array}$ & $\begin{array}{l}\text { Radiation } \\
\text { HARDNESS }\end{array}$ & Quality \\
\hline VITON & FPM/Generic & & Good & Not declared & Standard \\
\hline EPDM1 & EPDM/Generic & Sulfur & Fair & Not declared & Cheap \\
\hline EPDM2 & $\begin{array}{l}\text { EPDM/ } \\
\text { Dichtomatik (DE) }\end{array}$ & Peroxide & Good & Not declared & High quality \\
\hline EPDM3 & $\begin{array}{l}\text { EPDM/ } \\
\text { James Walker (UK) }\end{array}$ & Peroxide & Very good & $\begin{array}{l}1.6 \mathrm{MGy} \text { dose } \\
{ }^{60} \mathrm{Co} \text { gammas }\end{array}$ & $\begin{array}{l}\text { Certified as a } \\
\text { special material }\end{array}$ \\
\hline
\end{tabular}

\subsection{Lubricating oils and greases}

Table 2 is a list of lubricants to be tested for radiation hardness in mixed fields. The products must meet the following requirements to be selected for use in the SPES FE application: consistency NLGI grade must be between 0 and 3, and greases are required both for general purpose and high-vacuum applications. All products except Petamo GHY are rated as radiation resistant by the manufacturer, although testing and end-point conditions are not clearly specified. Krytox ${ }^{\circledR} 240 \mathrm{AC}$ is a hydrogen-free halogen that absorbs a lower dose than the other products in neutron fields. RG-42R-1 is a product rated as radiation resistant up to very high dose levels.

Table 2. Greases and base oils to be tested for radiation hardness in reactor mixed fields.

\begin{tabular}{|c|c|c|c|c|c|}
\hline Product (Class) & Manufacturer & $\begin{array}{l}\text { Base Polymer }+ \\
\text { thickener }\end{array}$ & $\begin{array}{l}\text { Consistency/ } \\
\text { Viscosity }\end{array}$ & $\begin{array}{l}\text { Radiation } \\
\text { Hardness }\end{array}$ & Quality \\
\hline $\begin{array}{l}\text { Grizzly Grease n.1 } \\
\text { (grease) }\end{array}$ & Lubcon (DE) & Mineral $+\mathrm{Li} / \mathrm{Ca}$ & NLGI 0 & $\begin{array}{l}1.2 \mathrm{MGy} \\
\text { gamma }\end{array}$ & Used at CERN \\
\hline $\begin{array}{l}\text { Petamo GHY } 133 \mathrm{~N} \\
\text { (grease) }\end{array}$ & Kluber (DE) & $\begin{array}{l}\text { Mineral oil + } \\
\text { polyurea }\end{array}$ & NLGI 2 & Not declared & $\begin{array}{l}\text { Standard SPES } \\
\text { product }\end{array}$ \\
\hline $\begin{array}{l}\text { Krytox }^{\circledR} 240 \text { AC } \\
\text { (grease) }\end{array}$ & $\begin{array}{l}\text { DuPont-Chemours } \\
\text { (USA) }\end{array}$ & $\begin{array}{l}\text { PFPE+PTFE, } \\
\text { H free }\end{array}$ & NLGI 2 & $\begin{array}{l}1.0 \mathrm{MGy} \text {, } \\
\text { reactor mixed } \\
\text { field }\end{array}$ & Hydrogen free \\
\hline RG-42R-1 (grease) & MORESCO (JP) & $\mathrm{PPE}+\mathrm{PC}$ & NLGI 1 & $\begin{array}{l}15 \mathrm{MGy} \\
\text { gamma }\end{array}$ & $\begin{array}{l}\text { High radiation } \\
\text { hardness }\end{array}$ \\
\hline RP-42R (base oil) & MORESCO (JP) & PPE & $\begin{array}{l}240 \mathrm{cSt} \text { at } \\
40^{\circ} \mathrm{C}\end{array}$ & $\begin{array}{l}15 \mathrm{MGy} \\
\text { gamma }\end{array}$ & $\begin{array}{l}\text { High radiation } \\
\text { hardness }\end{array}$ \\
\hline Apiezon-M (grease) & M\&I Materials & $\begin{array}{l}\text { Hydrocarbon, } \\
\text { halogen free }\end{array}$ & $\begin{array}{l}\text { molten grease } \\
413 \mathrm{cSt}, 50^{\circ} \mathrm{C}\end{array}$ & $\begin{array}{l}1.0 \mathrm{MGy} \\
\text { electrons }\end{array}$ & Ultra-high vacuum \\
\hline
\end{tabular}




\section{Experimental Protocol and Results}

\subsection{Dosimetry calculations}

Dosimetry calculations were performed using the Monte Carlo code MCNPX ${ }^{16}$ and two sophisticated models that reproduced the irradiation conditions in both the SPES FE complex and inside the irradiation channels of the TRIGA Mark II nuclear reactor. ${ }^{17}$

In a reference position in the target chamber, where the main elastomeric O-rings are located, the total absorbed dose in a 15-day irradiation period is approximately $0.26 \mathrm{MGy}$ for VITON (dose rate $0.70 \mathrm{kGy} / \mathrm{h}$ ) and about $0.70 \mathrm{MGy}$ for EPDM-based materials (dose rate $1.95 \mathrm{kGy} / \mathrm{h})$. Absorbed dose in mixed fields is strongly dependent on the material composition and in particular on the hydrogen content; this corresponds to $1.2 \%$ for VITON and approximately $7.5 \%$ for EPDM-based materials. The fraction of dose delivered by fast neutrons relative to the total dose is $60 \%$ for VITON and $85 \%$ for EPDM-based materials. The dose delivered by the gamma component is, by contrast, essentially independent of the material composition.

Lubricating oils and greases listed in Table 2 have different chemical compositions. The main components were evaluated by $\mathrm{CHN}$ analyses. The average hydrogen content is approximately $12 \%$ for non-fluorinated materials, whereas hydrogen is practically absent in fluorinated materials like Krytox ${ }^{\circledR}$. The most critical position for lubricating products in the FE structure is the main Acme screw of the target chamber pulling system that is the closest to the ${ }^{238} \mathrm{UC}_{\mathrm{x}}$ target. In the seven-year operating period of the FE, the total dose absorbed by non-fluorinated lubricating greases is about $25 \mathrm{MGy}$ (dose rate $1.0 \mathrm{kGy} / \mathrm{h}$ ). Fluorinated products with no hydrogen content would absorb only about 4.0 MGy $(0.2 \mathrm{kGy} / \mathrm{h})$. The foreseen doses absorbed by lubricants in the SPES FE raise the serious issues of a material's radiation hardness and the scheduled maintenance periods of the mechanical assemblies.

The dose rates absorbed by different materials in the main irradiating channel of the TRIGA Mark II reactor are as follows: $350 \mathrm{kGy} / \mathrm{h}$ for FPM elastomers, $680 \mathrm{kGy} / \mathrm{h}$ for EPDM-based elastomers, $\sim 900 \mathrm{kGy} / \mathrm{h}$ for non-fluorinated lubricants, and $300 \mathrm{kGy} / \mathrm{h}$ for fluorinated lubricants. As previously stated, non-hydrogenated materials are more transparent to neutron fields, and they may be considered for use in the presence of mixed irradiation fields.

\subsection{Results for elastomeric materials}

Samples of the four different elastomeric materials were irradiated in the reactor central thimble at four absorbed-dose values. Irradiation time durations were $0.5 \mathrm{~h}, 1.0 \mathrm{~h}, 2.0 \mathrm{~h}$ and $3.0 \mathrm{~h}$. One hour of irradiation corresponds to $0.34 \mathrm{MGy}$ absorbed dose for VITON and approximately 0.68 MGy absorbed dose for EPDM-based materials. These values are comparable to the typical doses absorbed in a 15-day irradiation period in the SPES FE.

Mechanical and physical properties of unirradiated and irradiated samples were tested to assess their evolution with absorbed dose. The measured mechanical properties were as follows: compression set, according to the ASTM D395-03 and ASTM D1414-94 
standards, expressed as the percentage of permanent deformation of the material after a prolonged application of strain; and material tensile properties, according to the ASTM D1414 standard, as elastic modulus, elongation at break, and tensile strength, which describe variations of stiffness, strength, and brittleness. Physical analyses performed were as follows: DSC calorimetry, IR analysis, DMTA analysis, swelling tests, and density measurement, the goal of which is the correlation of the variation of mechanical properties with the evolution of microscopic properties of the material.

Figure 3 depicts a sample of the results obtained. The evolution of compression set for the four materials under consideration is shown as a function of the absorbed dose.

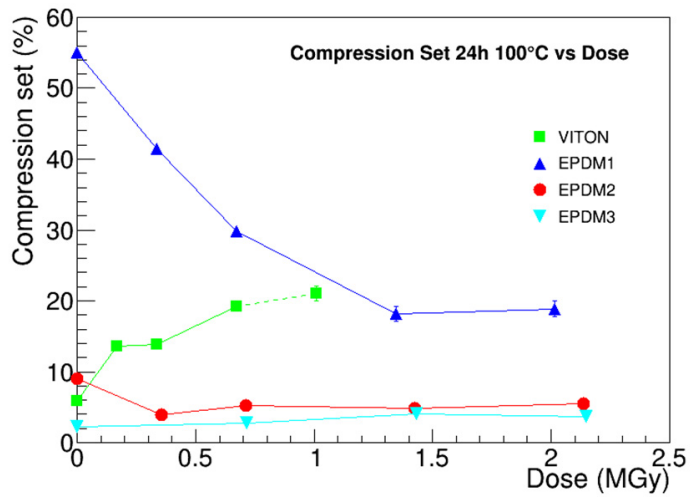

Fig. 3. Compression set values as a function of the absorbed dose for the four selected elastomers. The last segment of the line connecting VITON data is dashed since the material became brittle and fractured.

The VITON compression-set data indicates a rapid degradation of the material until a brittle failure. The EPDM1 features poor values of compression set, which improve from $55 \%$ to $20 \%$ at the highest value of absorbed dose. EPDM2 and EPDM3 values remain stable at a few percent of compression set values.

In Fig. 4, the evolution of elongation at break is reported as a function of absorbed dose. Elongation at break is the mechanical property that features the most important variations with absorbed dose. This could be a real issue, because elongation at break is related to the definition of elastomeric material. By definition, elastomeric materials must be able to elongate by at least $100 \%$ under stress, recovering their original shape when the deforming force is removed. For VITON, elongation at break decreases rapidly with absorbed dose from an average value of $400 \%$ of the initial value to about $50 \%$ at the highest value of absorbed dose. At $0.3 \mathrm{MGy}$, its value decreases below $100 \%$. For EPDM1, elongation at break for unirradiated samples is $500 \%$ and decreases rapidly with dose until about $80 \%$. At $1.5 \mathrm{MGy}$, its value decreases below 100\%. For EPDM2, elongation at break is $350 \%$ for unirradiated samples and decreases with dose to about $40 \%$. At $0.7 \mathrm{MGy}$, its value decreases below $100 \%$. The best performance is by EPDM3, whose unirradiated value is $280 \%$ and decreases to $70 \%$ at the highest value of absorbed dose. Its value decreases below $100 \%$ at $1.5 \mathrm{MGy}$. 


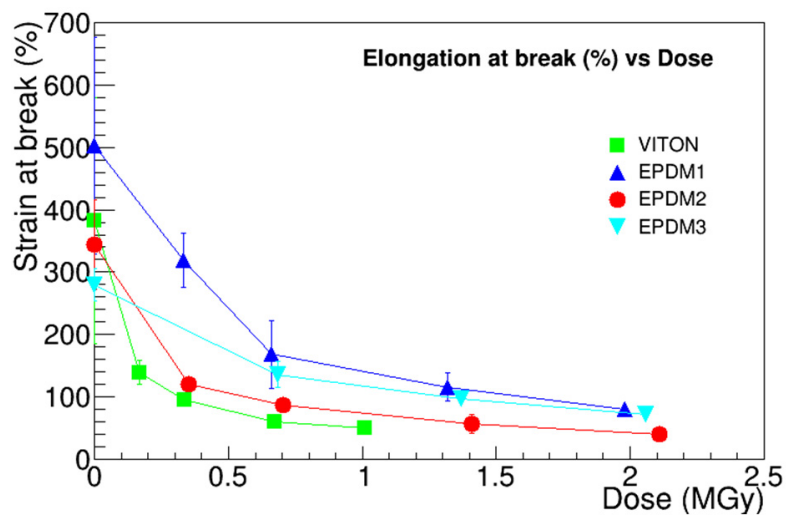

Fig. 4. Elongation at break values as a function of the absorbed dose for the four selected elastomers.

The presented results, together with others obtained during this study and reported elsewhere, ${ }^{18}$ allow the following conclusions to be drawn.

Because of the large difference in dose rates between accelerated and operating conditions (and therefore, in oxygen penetration during irradiation), the obtained results may have reliable predictive capability for those O-rings submitted to irradiation in vacuum conditions, such as the VAT valves' O-rings. For vacuum O-rings, which are exposed on one side to the atmosphere under service conditions, the results provide a guideline for the behavior of the materials under the same irradiation conditions.

VITON and EPDM1 (the latter is the standard SPES material) display the greatest variations of the tested mechanical properties with absorbed dose. In particular, when exceeding $0.26 \mathrm{MGy}$, the elastomeric properties of VITON deteriorate with dramatic increase of stiffness and brittleness. These materials are not recommended for use. An interesting result is that the three EPDM-based materials display different behaviors with absorbed dose, in spite of having the same base polymer. EPDM2 and EPDM3 display more stable mechanical properties with absorbed dose, apart from elongation at break that deteriorates to $25 \%$ of the initial value between $1.5 \mathrm{MGy}$ and $2.0 \mathrm{MGy}$ of absorbed dose. EPDM3, which is specifically designed for use in ionizing radiation environments, is the most stable, although the differences in performance relative to EPDM2 seem insufficient to justify the price difference for the target application.

\subsection{Preliminary results for lubricating greases}

Before planning systematic irradiation campaigns of the lubricating greases and base oils listed in Table 2, a set of preliminary tests was performed to verify potentially problematic behavior of the materials during irradiation. The following phenomena were tested: activation of the material under neutron irradiation, implying formation of radioactive waste that would require disposal; development of gaseous products and containment of the sample; and development of acidic gases or fluids. 
Concerning materials activation, both Neutron Activation Analyses (NAA) and radiologic-dose measurements were conducted. The results are encouraging, since most of the activated isotopes have short half-life, whereas only traces of long half-life isotopes, such as ${ }^{65} \mathrm{Zn}$, were found to be present in the irradiated samples. As a consequence, after 10-15 days of cooling, the contact dose of the irradiated samples was only $0.1-0.2 \mu \mathrm{Sv} / \mathrm{h}$, comparable to the natural background radiation. On the contrary, a huge gas evolution was measured in the irradiated samples, several times the original sample volume, which makes the containment of the products during irradiation critical. In addition, fluorinated products produce acidic gases, implying risks of corrosion in the environment, which would require specific remedial measures in the configuration of the irradiation set-up.

Tests of the evolution with absorbed dose of both mechanical and physical properties of the lubricating products are planned. The most relevant property of the base oils to be tested is dynamic viscosity, which is measured in centipoises (cP) by a viscometer, following the ASTMD445-06 standard. A radiation-induced increase in viscosity is expected. ${ }^{11}$ Lubricating greases are solid or semisolid two-phase systems, consisting of a thickening agent (soap) in lubricating oil (base oil). They are non-Newtonian fluids for which viscosity is not defined and measurable. The most frequently measured property characterizing grease quality is consistency (or consistency grade), which is measured by a penetrometer and expressed as tenths of millimeters of penetration of a metal cone into the surface of the material, following the ASTMD1403 standard. Grease consistency is expected to have a more complex behavior during irradiation: at lower dose values the grease is expected to soften due to the degradation of the gelling structure, and to harden at higher values of absorbed dose, due to cross linking of the base oil. Testing of the physical properties of irradiated greases is also planned, including testing rheological properties to document the non-Newtonian behavior and to measure relevant model parameters. ${ }^{19}$ Nuclear magnetic resonance measurements to document modifications of the chemical bonds with irradiation are planned as well.

An initial irradiation campaign was started using Grizzly Grease n.1, the standard lubricating grease used at CERN. At present, samples of about $8 \mathrm{ml}$ have been irradiated in the reactor's central thimble at values of absorbed dose of approximately $0.44 \mathrm{MGy}$, 0.89 MGy, and 1.77 MGy. Consistency was measured for unirradiated and irradiated samples. The consistency values for unirradiated samples corresponded well with the National Lubricating Grease Institute (NLGI) consistency grade 0, as declared on the product's data sheet. However, all of the irradiated grease samples were noticeably less consistent, almost behaving like fluids, with much higher values of penetration that registered outside of the penetrometer's scale. This is an intriguing result, since Grizzly Grease $n .1$ is rated by the manufacturer as being radiation resistant up to $1.2 \mathrm{MGy}$ in gamma fields. Whether this macroscopic difference is effectively due to the different radiation fields employed or to other testing conditions is a question of both practical and scientific interest. Further measurements on this and other products may shed light on this interesting issue. 


\section{Conclusions}

Experimental studies of radiation hardness in reactor mixed fields of materials to be employed in the construction of the SPES facility at LNL have been started. A study of elastomeric materials to be used for vacuum O-rings was completed, and the main results are documented in this paper. A study of lubricating oils and greases has been initiated; the preliminary results indicate that the radiation damage induced by reactor mixed fields may be different from pure gamma fields, contrary to a generally accepted assumption.

Recently, the Materials Group of the Target Division of the European Spallation Source (ESS), a European Research Infrastructure Consortium (ERIC), has joined the project with the aim of exploiting the synergies in the common problems of materials radiation resistance of the two facilities, which are presently under construction.

The results of the present work, in addition to their significance to the target applications, provide original data on the radiation hardness and behavior of organic technical materials in irradiating conditions different from those usually employed for accelerated-aging tests.

\section{Acknowledgements}

This work was supported by Legnaro National Laboratories of INFN (Padua), the University of Brescia, the University of Pavia, and the INFN Pavia, Italy and ESS ERIC, Lund, Sweden.

\section{References}

1. G. Prete et al., EPJ Web of Conferences 66, 11030 (2014).

2. A. Andrighetto et al., Eur. Phys. J. A 25, 41 (2005).

3. A. Andrighetto et al., Eur. Phys. J. A 30, 591 (2006).

4. S. Corradetti et al., Eur. Phys. J. A 49, 56 (2013).

5. A. Monetti et al., Eur. Phys. J. A 51, 128 (2015).

6. M. Ballan, Master's Degree Thesis, Università degli Studi di Padova (2014).

7. F. Guarino, C. Hauviller, M. Tavlet, Yellow Report CERN-2001-006, Part 4 (CERN, Geneva, 2001).

8. R.L. Clough and K.T. Gillen, J. Polym. Sci., P. C. Ed. 23, 359 (1985).

9. V. Plaček et al., Polym. Test. 28, 209 (2009).

10. F. Le Lay, Radiat. Phys. \& Chem. 84, 210 (2013).

11. R.O. Bolt and J.G. Carrol, Radiation Effects on Organic Materials (Academic Press, 1963).

12. C.D. Bopp and O. Sisman, Radiation Stability of Plastics and Elastomers (Suppl. to ORNL928), ORNL Report 1373 (Oak Ridge National Laboratory, 1953).

13. Sealing Elements - Technical Handbook O-rings (ERIKS, 2015).

14. P. Beynel et al., Yellow Report CERN-82-10, CERN, Part 3 (CERN, Geneva, 1982).

15. G. Lee, IEEE Trans. Nucl. Sci. NS-32(5), 3806 (1985).

16. D. B. Pelowitz, ed., MCNPX ${ }^{T M}$ USER'S MANUAL, Version 2.7.0, LA-CP-11-00438 (Los Alamos National Laboratory, 2011).

17. A. Andrighetto et al., SPES-Note-WPB06_04_0003/RDS-SPES, June 2016, www.lnl.infn.it/ $\sim$ spes_target/.

18. A. Zenoni et al., Rev. Sci. Instrum. 88, 113304 (2017).

19. A.V. Radulescu and I. Radulescu, ISSN 1392 - 1297, MECHANIKA 3(59), 67 (2006). 